\title{
Assessment of suspended growth biological process for treatment and reuse of mixed wastewater for irrigation of edible crops under hydroponic conditions
}

4 Precious N. Egbuikwem ${ }^{\mathrm{a}, \mathrm{b}^{*}}$, Jose C. Mierzwa ${ }^{\mathrm{c}}$, Devendra P. Saroj ${ }^{\mathrm{a}^{*}}$

$5 \quad{ }^{a}$ Department of Civil and Environmental Engineering, Faculty of Engineering and Physical

6 Sciences, University of Surrey, Guildford GU2 7XH, United Kingdom.

$7 \quad{ }^{\mathrm{b}}$ Department of Agricultural and Environmental Engineering, School of Engineering

8 Technology, Imo State Polytechnic Umuagwo, P. M. B. 1472, Owerri, Nigeria.

$9 \quad{ }^{\mathrm{c}}$ Polytechnic School, Department of Hydraulic and Environmental Engineering. Av. Almeida

10 Prado, 83 - Building, Civil Engineering / PHA Butanta 05508-900, University of Sao Paulo,

11 Sao Paulo, SP, Brazil.

DOI: https:// doi.org/ 10.1016/ j.agwat.2020.106034

13 Agricultural Water Management, Volume 231, 31 March 2020, 106034

14 Abstract

15 Due to the increasing freshwater deterioration and demand for irrigation, there is pressing need to reclaim and reuse wastewater for agricultural operations. While this practice is gaining significant traction in developed world, it is quite rare in most developing countries with inadequate or no functional sewerage facilities and treatment systems at both municipal and industrial levels occasioned by high investment and operational costs. Consequently, wastewaters generated are in complex heterogenous mix of industrial, domestic, municipal and agricultural runoff wastewater. Biological technologies which utilize the expertise of microorganisms are considered robust, efficient and economically attractive for treatment of wide range of wastewaters and they have high suitability in developing countries. This work therefore assessed the potential of suspended growth biological process (SGBP) for reclamation and reuse of mixed wastewater composed a mixture of domestic effluent, pharmaceutical, textile, petroleum discharges and agricultural runoff for irrigation of edible crops (lettuce and beets) with plants phenological parameters as measuring indicators. The germination and phenological characteristics of crops were studied in a hydroponic unit under four (4) irrigation regimes vis., tap water as control, mixed wastewater, SGBP treated 
wastewater and tap water with nutrient solution as upper control for a duration of $45-d$. The experiments were conducted at the Centre for Environmental Health Engineering, University of Surrey. The results proved that the SGBP treated wastewater had no negative impact on germination responses of the seed crops. However, residual recalcitrant compounds exerted toxic effects on germinated seedlings causing early stunted growth in plant root systems with resultant limited access to nutrients. Consequently, plant vegetative growth and phenological development as well as chlorophyll production were reduced. In comparison to nutrients supplemented solution, nutrients deficiency and imbalance in treated wastewater contributed to the poor development in irrigated plants. Following the seed germination and plant growth outcomes, there is a positive indication for reuse of mixed wastewater in agriculture. However, there is need for further research to explore the benefits and limitations of reusing such treated wastewater.

Keywords: Aerobic biological processes, mixed wastewater treatment, wastewater reuse, hydroponic agriculture, vegetable production, water scarcity

\section{Introduction}

Wastewater reuse in agriculture is gaining significant traction across the globe as economically and environmentally sound water resources management technique to cope with the ever-increasing freshwater pollution and demand, particularly for agriculture. Agricultural irrigation is ranked topmost in water consumption rating, accounting for nearly $70 \%$ of global freshwater supply (FAO, 2017) with 15\% additional withdrawal by 2030 (United Nations, 2017; World Bank, 2017) and which will further intensify the global water scarcity crises especially in arid and semi-arid regions. In another view, wastewater contains essential nutrients and organic matter that are beneficial to the plants (Khan et al., 2011; Ruma \& Sheikh, 2010) and therefore has been identified as a valuable input resource for increased agricultural production at reduced costs.

While proximity obviously poses big challenge to water reuse in agriculture by limiting its practice as most treatment facilities are sited far away from agricultural fields, the reuse programme is also rarely practiced in developing countries as there are limited sewerage 
systems in place and the technologies to reclaim the wastewaters are lacking due to huge capital and operational costs. In West Africa, and Nigeria precisely, a cross sectional data from the 2013 demographic and health survey indicate that only 5.3\% household is connected to the sewers (Abubakar, 2017). Similarly, according to the World Bank report on Nigeria Water Supply, Sanitation, and Hygiene Poverty Diagnostic, only 5.6\% of the population make use of sewerage facilities (World Bank, 2017), consequently, the environment serves as direct and default recipient of most domestic and sanitary wastes generated (Gandy, 2006). M oreover, many of the industries have little or no adequate treatment systems to manage their produced wastes and have converted the environment, adjacent water bodies and publicly owned sewers to primary receptacles of varying streams of hazardous industrial wastes (Kanu and Achi, 2011). Consequently, wastewaters generated from such settings are in complex heterogeneous matrix composed a mixture of industrial discharges, domestic wastewater, municipal and agricultural runoff (Kanu and Achi, 2011), thus creating the necessity for treatment with suitable technologies for possible reuse in agriculture.

Wastewater treatment systems span between two polarised methods including biological and physicochemical processes. The choice of treatment methods is largely constrained by amongst others investment and operational costs, wastewater source and quality, and intended water reuse. The chemical based technologies such as the advanced oxidation processes (AOPs) have proven potential over the biological processes for removal of organic complexes and recalcitrant compounds in industrial waste streams (Hey, 2013; MéndezArriaga et al., 2009; Stepnowski et al., 2002). However, their application in wastewater treatment is limited due to the associated high energy and chemical requirements. In comparison, the biological processes are robust, efficient and cost-effective, and with the application of suitable bacterial culture and process conditions have in some cases proven efficient for degradation of persistent organic pollutants (Varjani, 2017; Popa et al., 2014; Chaudhry and Chapalamadugu, 1991). To this end, biological technologies which apply the principle of nature with specific or mixed bacterial strains have remained the economic, efficient and sustainable means of decontaminating most human generated wastes and anthropogenic pollutants and are promising for emerging pollutants. 
88 One area of concern relating to biotechnology application in wastewater treatment (especially industrial wastewater) at the present time of freshwater crises is the suitability of the treated water for agricultural reuse especially for crop irrigation. M eanwhile, the stability of some chemical compounds in wastewater treatment coupled with the reported and possible bioaccumulation of toxic elements in edible plants tissues have prompted the World Health Organisation to issue guidelines limiting use of chemical-based industrial wastewaters for irrigation of crops, and where wastewater is reused for agriculture, practices that entail mixing of industrial and domestic wastewaters should be avoided (WHO, 2006). Noteworthy, industry is an area with heavy water demand currently utilizing nearly 22\% (du Plessis, 2017) of freshwater supplies, and equally generates considerable volume of liquid wastes. Agriculture on the other hand accounts for nearly $70 \%$ of freshwater withdrawal (FAO, 2017). Therefore, a holistic water reuse in agriculture which entails reclamation and reuse of streams from various sources is paramount and key for saving precious freshwater resources from the increasing pressure of depletion and imminent dryness. Hence, for extensive and sustainable water reuse programme especially in developing countries of Asia, Africa, and Latin America where segregation of industrial discharges from domestic effluents is currently poorly or not practiced, effluents from both industrial, municipal, domestic and other sources can be collected and reclaimed for agricultural irrigation using suitable and cost-effective technologies. Interestingly, activated sludge technology characterised as a mixed culture engineered system has been largely explored for potential application in treatment and reuse of industrial and domestic wastewaters for crop irrigation and promising results have been obtained (Libutti et al., 2018; Cirelli et al., 2012).

Meanwhile, wastewater reuse for agriculture is facing setbacks relating to public acceptance of produce from such operation following reports of their potential health risks (Saliba et al., 2018). In recent years, researchers have focused on assessing the reusability of biologically

113 treated domestic and industrial wastewaters by ascertaining the quality of the produce for human consumption. Libutti and co-workers demonstrated that agro-industrial wastewater can be effectively reclaimed by biological treatment processes and potentially reused for irrigation of edible crops (broccoli and tomatoes) with no significant impact on crop quality

117 (Libutti et al., 2018). Similarly, biologically treated domestic wastewater was reported a

118 valuable irrigation source for cultivation of lettuce crop with no compromise on the quality of 
119 the edible parts (Urbano et al., 2017). However, other studies have highlighted possible 120 ecological risks in sewage irrigated agriculture as there is increased window for 121 bioaccumulation of persistent organic pollutants, polyaromatic hydrocarbons, heavy metals 122 and other toxic elements in the edible food (Chung et al., 2008; Khan et al., 2008).

123 It is acknowledged that wastewater reuse for irrigation has well been studied both at field 124 scale, greenhouse and laboratory levels, but all were mainly on domestic and municipal sourced wastewater with little work on reuse potential of complex mixed streams being the scenario in most developing countries. To the best of the current knowledge, no study has been conducted on application of suspended growth biological processes for treatment and reuse of mixed industrial, domestic and agricultural runoff wastewater for crop irrigation. This is an important research area which needs to be investigated in a systematic experimental research. The hypothesis for this research is that the suspended growth biological process can reduce the level of pollutants presented in mixed wastewater up to the extend that it can be reused in agriculture. The requirement of further treatment might also play a role depending upon the exact scenario of water reuse.

This study therefore seeks to assess the threshold capability of low-cost suspended growth biological process in improving the quality of mixed industrial, domestic and agricultural runoff wastewater (domestic, pharmaceutical, textile, petroleum and agricultural runoff), and test the hypothesis of reusability of the treated effluent for irrigation of edible crops with plants phenological and physiological parameters as measuring indicators. Specific objectives include to (i) simulate representative mixture of domestic, pharmaceutical, textile, petroleum and agricultural runoff as may be obtainable in developing countries and practicable in labscale biological treatment systems (ii) treatment of the simulated mixed wastewater using low-cost suspended growth bioreactor operated at complete aeration (iii) cultivation of vegetable crops (lettuce and beets) using the treated wastewater under hydroponic conditions to better understand the impact of biologically treated effluent on phenological characteristics of edible crops.

\section{Materials and methods}




\subsection{Composition and characteristics of simulated mixed wastewater}

The raw effluent was a model mixture of petroleum, textile, pharmaceutical, domestic and agricultural runoff wastewater. The composition and chemicals used in simulating the various waste streams into a single mix is detailed in previous study (Egbuikwem et al., 2019). The overall characteristics of the raw mixed wastewater is presented in Table 1 . The high nutrients load simulates agricultural runoff water from cultivated fields and livestock operation.

\subsection{Experimental set-up}

The experimental study was conducted at the Centre for Environmental Health Engineering (CEHE), University of Surrey, United Kingdom. The suspended growth bioreactor was operated for a period of 223 days, spanning from June 2018 to January 2019, while the hydroponic cultivation lasted for 45 days, from April to M ay 2019. The hydroponic cultivation was carried out once in four (4) replicates.

A schematic set-up of the laboratory scale suspended growth bioreactor (SGBR) and the hydroponic unit is presented in Figure 1. The SGBR consisted of a $3.5 \mathrm{~L}$ (working volume) aeration tank, feeder tank (10 L), aquarium pumps with air diffusers for supply of required oxygen and to maintain adequate mixing. The bioreactor was inoculated with a mixture of active sludge seeds and wastewater sourced from Thames wastewater treatment works, Reading, United Kingdom, and operated under continuous aeration for adaptation to the simulated mixed wastewater. The bioreactor operating conditions are presented in Table 2. The performance bioreactor with respect to pollutants removal was assessed on bulk parameters such as COD and $\mathrm{BOD}_{5}$.

The hydroponic unit (4 sets) consisted of cultivation unit with LED light, sprout box with lid, cultivation insert set, starter plug made from rockwool, pumice stones, and nutrient solution.

171 The units were purchased from IKEA store Reading, United Kingdom and redesigned for use for the present study. Organic vegetable seeds including lettuce Paris Island Cos (lactuca sativa) and Beets White Silver 2 (Beta vulgaris) were purchased from MolesSeeds, United Kingdom and used in this study following grower's recommendation. Aquarium air pumps (Interpet Aquarium Air pump - AP4) which provided the adequate dissolved oxygen in the irrigation solutions for the plant root systems were purchased from Amazon, United Kingdom. Lettuce and beets plants were grown simultaneously under four (4) treatment solutions vis., 
178 Mixed Wastewater (MWW), Treated Effluent (TE), Tap Water (TPW), and Tap Water plus

179 Nutrient Solution (TPW +NUS) as control; and each had four (4) replications.

180 2.3. Description of sectional units of hydroponic system

181 The hydroponic system comprised of different sections including cultivation unit with LED 182 light, sprout box, cultivation insert set, growing media (rockwool plug and pumice stones), 183 and nutrient solution. The LED light colour spectrum consists of $25 \%$ blue, $35 \%$ green and $40 \%$ red light, and provides an average of $100 \mu \mathrm{mol} / \mathrm{m}^{2} / \mathrm{s}$ PPFD (IKEA, 2019). The nursery box is a rectangular chamber (5.5 L capacity) attached with a rectangular platform having 50 cylindrical holes of $25 \mathrm{~mm}$ diameter and $20 \mathrm{~mm}$ depth, and a transparent humidity lid. The rockwool plugs ( $20 \mathrm{~mm}$ diameter and $27 \mathrm{~mm}$ height) have inverted cone shape at the top end in which seeds are sown. The receiving box (nursery box) holds the irrigation solution for seed germination. The insert set is a near rectangular box ( $3 \mathrm{~L}$ capacity) with detachable trapezoidal-shaped basket pots (8nos) in which the germinated seed plugs are inserted, transplanted and supported for further growth. The pots are of dimensions $3.8 \times 5.5 \times 5.2 \mathrm{~cm}$ as base width, top width and height respectively. The pots which retains the growing media (pumice stones) have about 96 openings of $85 \times 17 \mathrm{~mm}$ as length and width. The insert set has a water level indicator for guide on when and what amount to irrigate and, and water is applied through an attached plastic funnel. The properties and compositions of the growing media (rockwool and pumice stones) and size distribution of pumice stones are presented in Tables B1 and Fig A1 (supplementary data) respectively.

\subsection{Plant selection}

The lettuce (lactuca sativa) and beets (beta vulgaris) crops are widely grown and eaten green vegetables across the globe, and commonly eaten in Europe, because of their high nutritive values. The plants have fast germination and growth traits and can be characterized as leafy vegetables (Khan et al., 2008). In addition, lettuce and beets have relatively short maturity periods which qualifies them suitable for lab scale research purposes on treated wastewater reusability under hydroponic conditions, and therefore were chosen for the present study.

\subsection{Sources and characteristics of irrigation water solutions}

Four (4) different irrigation solutions namely; Tap Water (TPW), M ixed Wastewater (M WW), 
this investigation. The tap water (control) was sourced from Civil and Environmental Engineering water laboratory, University of Surrey, United Kingdom. The MWW consisted a mixture of domestic, pharmaceutical, petroleum, textile waste streams and agricultural runoff wastewaters and maintained the same characteristics as reported in previous study (Egbuikwem et al., 2019). The TWW was effluent from the lab-scale suspended growth biological process, while the TPW +NUS (which served as the upper reference control for the study) was a balanced nutrients solution prepared in the recommended ratio of $4 \mathrm{~mL}$ of fertilizer solution to $1 \mathrm{~L}$ of tap water (IKEA, 2019). The composition of the nutrient solution is stated in Table $\mathrm{Cl}$ (supplementary data) and the physicochemical and microbial characteristics of the irrigation streams are presented in Table 3.

\subsection{Seeds planting and growth in hydroponic units}

Healthy and uniformly sized seeds of lettuce and beets were hand-picked and planted for trial runs to ascertain the seeds viability and suitable conditions for germination. Following the trial study, the beet seeds were pre-treated by soaking for 5 -h while the lettuce seeds were soaked for an hour in the respective irrigation solutions vis., TPW as control, TWW, MWW and TPW + NUS (as upper reference limit) prior to planting. Following the grower's recommendations in (IKEA, 2019), the rockwools were selected and submerged in the respective treatment solutions for half an hour and transferred to the sprout box for seed planting. The pre-soaked seeds were sowed onto the rockwool plugs with one seed per plug and ten (10) seeds of the same species were planted for each treatment. The seeds were covered with transparent plastic humidity lids (to retain moisture and increase/maintain surrounding temperature) and placed under LED cultivation lighting. The seeds were germinated under 12/12-h light/ darkness at an average temperature and relative humidity of $20.3 / 14.9^{\circ} \mathrm{C}$ and $54 / 40 \%$ daytime/night-time respectively. Germination was monitored and counted on daily basis at every 12:00 hour for 10 days, and germination conditions were in line with germination reports for beets and lettuce (Reddy, 2019; Brechner and Both, 2013).

234 Following previous method (Deng et al., 2014) emergence of seed radicles to $5 \mathrm{~mm}$ elongation was used as a measure for seed germination.

236 Upon full emergence and establishment of 2 - 3 leaves on day 11, four (4) good quality 237 seedlings from each of the studied seeds and treatments were transplanted to the insert-set 
arranged in a complete randomised block design for further growth and phenological studies spanning up to 5 weeks. Irrigation was applied when the water level indicator showed minimum and water was replenished to maximum level. Each treatment solution was continuously aerated using aquarium pumps and air diffusers to ensure adequate dissolved oxygen in the plant root systems. The seed germination and phenological development were studied and relevant data were collected.

\subsection{Data collection and analytical procedure}

\subsubsection{Characterization of irrigation streams/ solutions}

The physicochemical and microbial qualities of the irrigation solutions including tap water, mixed wastewater, treated wastewater and tap water with nutrients solution were analysed following the standard methods for the examination of water and wastewater (APHA, 1998) and specified in previous study (Egbuikwem et al., 2019).

\subsubsection{Germination and Phenological characteristics of plants}

Seed germination and plant phenological characteristics were collected between two distinct growth stages vis., initial stage and crop development stage (Allen et al., 1998). The various phenological parameters studied include., germination, emergence of leaves and leaf numbers, leaf area measured as length and width, shoot length and root length. Following the growth information in (Reddy, 2019; Brechner and Both, 2013), germination was studied for 10 days. Seed germination was recorded daily, and germination rates were calculated. Leaf development was monitored, and leaf number was counted on weekly basis from plant base to top. The leaf size (length and width), shoot and root lengths were measured at the end of the study period following the method adapted from (Elfanssi et al., 2018). For accuracy in data collection, the length and width of the $4^{\text {th }}$ leaf from base in each replication and treatment were measured using a flexible measuring tape. The shoot length was measured from the top of rockwool to the tip of most fully developed leaf while the root length was measured from the top of rockwool to the tip of the longest root.

\subsubsection{Fresh weight, dry weight and chlorophyll estimation}

The vegetable leaves from the various treatments were harvested on the $5^{\text {th }}$ week after transplant in their individual replications. Afterwards, the leaves were air dried at room temperature for $60 \mathrm{~min}$ and weighted on a high resolution balance to determine the leaf fresh 
weights (LFW), and later oven-dried at $70^{\circ} \mathrm{C}$ for $48-\mathrm{h}$ for dry matter estimation (LDW) (Elfanssi et al., 2018). The chlorophyll contents of the vegetable leaves of the various treatments were quantified following the method used in previous study (Banik et al., 2018). Similar parts of the third leaf of each replicate of the four treatment solutions were cut with scissors and processed for chlorophyll analysis. The green pigments were extracted in $80 \%$ acetone and homogenise at 8,000 rpm for $60 \mathrm{~min}$ using a centrifuge (HERAEUS MEGAFUGE 16R). The optical densities of the supernatants were measured using a UV-Vis spectrophotometer (biochrom - Libra S60) at 645 and $663 \mathrm{~nm}$ and chlorophyll a, b and total chlorophyll were calculated using the following relationships;

Chl.a (mg/g fresh wt.) $=[12.7($ abs 663) $-2.69($ abs 645)] xV/1000xW

Chl.b (mg/g fresh wt.) $=[22.9($ abs 645$)-4.68(a b s 663)] \times$ V/ 1000xW

Total Chl. $=(\mathrm{mg} / \mathrm{g}$ fresh wt.) $=[20.21($ abs 645$)+8.02($ abs 663$)] \times \mathrm{V} / 1000 \times \mathrm{W}$

Where $\mathrm{V}=$ volume of extract $(\mathrm{ml})$

$\mathrm{W}=$ weight of fresh leaf tissue $(\mathrm{g})$

\subsection{Statistical analysis}

The data relating to plants phenological development and green pigments production due to the applied treatment solutions were subjected to analysis of variance (ANOVA) at $P=0.05$, using M icrosoft excel. The means were compared using the t-test at 5\% significance level.

\section{Results and Discussion}

\subsection{Steady-state performance of suspended growth biological process}

The laboratory-scale aerobic bioreactor was operated for a period of 7 months with extended acclimation lasting up to 98 days. Following the very low biodegradability (BOD $5 / C O D: 0.13$; F/M : $0.05 \mathrm{~d}^{-1}$ ) of the synthetic mixed wastewater, prolonged biological adaptation was considered essential to enhance biodegradation of organic pollutants in the complex water matrix (Dvorak et al., 2013). The bioreactor was operated for about 4 weeks to ensure a complete phase-out of dilution effects of inoculant municipal wastewater. The operated SRT of 21-d and weekly removal of excess sludge were instrumental to the near constant M LSS and MLVSS concentrations of 4540 and $2460 \mathrm{mg} / \mathrm{L}$ maintained in the biological unit 
296 throughout the experiment. During acclimation, the system performance varied widely 297 potentially due to adaptation of the biological po pulations and which was optimally stabilized 298 upon attainment of full adaptation which was much evidence on organics and nutrients 299 removal dynamics. Through the extended biomass acclimation period, residual organics varied between 81.5 and $251 \mathrm{mgCOD} / \mathrm{L}$, and 12.6 and $53.7 \mathrm{mgBOD} 5 / \mathrm{L}$ as maximum and minimum concentrations respectively following phase-out of dilution effects. The details of bioreactor response and behaviour from start-up to acclimation stage are reported in previous study (Egbuikwem et al., 2019).

Figures $2 a$ presents the performance of the suspended growth biological process for organic carbon removal in mixed domestic and industrial wastewater, while Figures $2 b$ and $2 c$ report the nutrients removal trend in the treatment system. Figure $2 \mathrm{~d}$ shows the $\mathrm{pH}$ variation throughout the experiment while other physicochemical characteristics of the treated effluent at steady-state are presented in Table 3.

Upon full acclimation and arrival to stable state, high and near stable COD and $\mathrm{BOD}_{5}$ removal were maintained, amounting to 85.4 and $87.0 \%$ removal on average respectively. The average residual COD at steady-state was $209.0 \pm 5.2 \mathrm{mg} / \mathrm{L}$ which probably represents the nonbiodegradable and higher molecular compounds of hydrocarbon origin. The high biodegradation potential of the SGBP for the studied complex wastewater could be by induced extracellular enzymes with the primary function of degradation of complex organic compounds (Cadoret et al., 2002). Comparable carbon consumption in activated sludge process treating petroleum refinery wastewater has been reported in previous study (Amin 317 et al., 2012).

Similarly, nitrification, total nitrogen and phosphorus removal were all nearly stable at steadystate with average removal of $58.4,62.3$ and $76.7 \%$ respectively. The high nutrients removal in such a complex mix is a product of biomass/microbial adaptation to extreme conditions of the synthesised mixed stream containing recalcitrant compounds. The finding is in agreement with previous reference (Dvorak et al., 2013) in which extended biomass exposure to industrial wastewater condition was instrumental to resuscitation of nitrification activities resulting to considerable ammonium consumption. Denitrification activity was marginally inhibited due to the prevailing redox condition (continuous aeration) in the treatment thus 
326 leading to accumulation of nitrate in the treated effluent with average concentration of

$32722.8 \pm 3.5 \mathrm{mg} / \mathrm{L}$ at steady-state.

328 Effluent salinity quality measured in terms of total dissolved solids (TDS) and electrical conductivity (EC) did not vary widely from the influent concentration, and average of 493 $\mathrm{mg} / \mathrm{L}$ and $993.0 \mu \mathrm{S} / \mathrm{cm}$ were measured at stable condition respectively. This was not a surprise as activated sludge processes are not suitable treatments for removal of salinity in wastewater, rather neutralisation and precipitation (Lu et al., 2011). Meanwhile, electrocoagulation has been reported to complement the biological treatment for reduction of TDS and EC in petroleum refinery wastewater treatment (El-Naas et al., 2016). The total residual solids measured as TSS and turbidity considerably reduced by 73.7 and $87.6 \%$. The $\mathrm{pH}$ of the system varied between 5.64 and 8.20 during the acclimation period (Figure $2 \mathrm{~d}$ ) and a neutral condition was reached at stable state with $7.01 \pm 0.3$ on average. The observed variation in $\mathrm{pH}$ was a consequence of effective nitrification and subsequent feed bicarbonate supplements thus leading to consumption and regain of alkalinity (Egbuikwem et al., 2019).

In comparison to United States Environmental Protection Agency (US EPA) water reuse criteria and South African (S. A.) water quality standards for irrigation presented in Table 3, the concentrations of the monitored water quality parameters in treated wastewater were above both the international and national guidelines except for $\mathrm{pH}$. However, while the overall water quality was not ascertained, the treated wastewater may not be totally considered unfit for crop irrigation. Therefore, there is need for reuse of bioreactor effluent to ascertain its suitability and potential for irrigation.

\subsection{Germination of lettuce and beet seeds and conditions of plant growth}

348 The climatic conditions in terms of temperature and relative humidity $(\mathrm{RH})$ prevailing throughout the plant growth period were monitored and found varied from $15.4-21.8^{\circ} \mathrm{C}$ and $35-51 \%$ (Figures $3 a$ and $3 b$ ) respectively. Temperature and $\mathrm{RH}$ play a critical role in plant growth and development. The former controls the plant chemical processes and growth through the activity of enzymes which performs best at narrow temperature ranges. While the latter influences plant transpiration rates and consequently, the transport of nutrients and minerals from roots through to the leaves (Brechner and Both, 2013). The temperature values are within the ranges reported to have no negative effects on germination and growth 
356 of the studied seed crops (Pothour, 2017; Gray, 1975). Considering that, it can be asserted

357 that temperature and relative humidity conditions had no significant negative impact on the 358 plants all through the developmental stages.

359 The impact of treated mixed wastewater (TWW) on lettuce and beets germination in relation to the control solutions (TPW) and (TPW +NUS), and untreated mixed wastewater is reported in Figures $3 c$ and $3 d$. The rate of germination was rapid in lettuce seed and faster in TPW + NUS treatment, attaining a complete germination in day 2 while seeds treated with TPW, TWW and MWW achieved a $100 \%$ germination in day 3 . However, seeds irrigated with MWW displayed some features of delayed germination as only 3 out of 10 seeds planted sprouted in day 2 at the time of data collection. This result was expected as the raw wastewater was characterised by high organic load and diesel fuel with high tendency of creating oxygen limited environment and physically obstruct oxygen and water transfer between the seed and surrounding water environment (Adam and Duncan, 2002), and which consequently inhibits seeds germination and sprout.

Unlike the germination trends in lettuce which were rapid and nearly identical, germination rates in beets under the studied treatment solutions were slow and non-uniform with a maximum germination of $80 \%$ recorded in day 10 in TPW + NUS treatment. Germination in TPW and TWW did not vary significantly at 5\% level of significance and a maximum of $60 \%$ germination was attained in both solutions at the end of germination period (day 10). Germination in M WW was very low with only $30 \%$ recorded in ten days. The poor germination responses in MWW treated crops was in part due to phytotoxic of diesel fuel and inhibitory effects of diesel oil $(840 \mathrm{mg} / \mathrm{L})$ in addition to soy oil $(22.4 \mathrm{mg} / \mathrm{L})$ in the mix which may have created a thin oil film barriers around the seeds and consequently reduced or hindered air movement into the seeds as well as plant access to water and nutrients (Noni-M orales et al., 2019; Ogbo, 2009; Adam and Duncan, 2002). M oreover, polyaromatic hydrocarbons are toxic to plants with high tendency of affecting plant growth adversely throughout the developmental stages especially at the critical stages of seeds germination and roots formation (Kummerová et al., 2012). In addition, high organic loads in MWW may have contributed to the suppressed germination in lettuce and beets. Nonetheless, volatile fraction 
another study to have play a critical role in poor germination and delayed seed emergence

The rapid germination rates in lettuce seeds irrespective of the treatment solution could be aligned partly with the seed physical characteristics having very soft pericarps thus allowing germination at slightest available moisture. The slow germination rates in beets may be a display of physical dormancy resulting from the less impermeable inherent seed coats, as they tend to restrict germination by being barriers to water and oxygen movement into the seed as well as exert mechanical resistance to radical emergence (Chaves et al., 2017). However, the germination results show that seeds of different groups and species have varying degrees of toxicity threshold and which is in agreement with (Ogbo, 2009) who found that phytotoxicity of hydrocarbons (diesel oil) vary between different seed crops. In both seed germination studies, TWW demonstrated potential for crop irrigation as its impact on lettuce and beet seeds germination did not vary significantly with the TPW at $5 \%$ level of confidence. However, the reuse potentials of the TWW can only be ascertained following plants overall growth assessments and quality of produce for human consumption.

\subsection{Leaf number and enlargement of lettuce and beets}

Data relating to leaf numbers and leaf sizes are presented in Figure 4 . The average leaf number for lettuce on week 5 after transplant were 9, 6, 8 and 25 for TPW, M WW, TWW and TPW + NUS respectively. In the same order, the beets were 7, 4, 6 and 11 with the MWW indicating an average of two (2) replicates as the other two replicates remained inhibited (no emergence of leaves).

407 With reference to the balanced nutrients solution (TPW +NUS), the results show that the low leaf production in TWW irrigated plants was mainly due to nutritional deficiency as similar poor vegetative development was recorded for TPW (no significant difference in leaf numbers existed between the TWW and TPW at 5\% confidence level). The impact of nutrients imbalance in the irrigation solutions was apparent by the symptoms of yellow coloration observed in both plants with TPW and TWW irrigation. This result is in agreement with that obtained in similar studies (Jesse et al., 2019; Carvalho et al., 2018; Chow et al., 2001) in which poor vegetative development and yellow colouration in lettuce crops irrigated with treated wastewater was aligned to nutrients deficiency and imbalance as wastewater with nutrients 
416 supplement performed very excellently. However, the comparable leaf number in TPW to

417 TWW in the present study, irrespective of higher nutrient contents over the TPW was an

418 indication of plants limited access to nutrients caused by the organics and toxic compounds

419 in wastewater. The high concentration of complex organics and hydrocarbon compounds 420 were the cause of the inhibition, stunted growth and suppressed leave emergence observed

421 in MWW irrigated crops.

422 Similarly, the sizes (length and width) of leaves grown under the nutrients supplemented

423 irrigation regime were consistently larger in both lettuce and beets throughout the growth 424 period and the plants can be characterized as physically very healthy and thick with an 425 average of 11.8 and $4.75 \mathrm{~cm}$, and 13.3 and $5.05 \mathrm{~cm}$ as leaf lengths and widths for lettuce and 426 beets respectively; as against the 2.1 and $1.3 \mathrm{~cm}$, and 3.4 and $1.7 \mathrm{~cm}$ leaf sizes recorded in 427 the same order in TWW plants. While the observed fast growth rate and leaf enlargement in 428 plants with TPW + NUS could (highlight the nutritive value of the nutrient supplemented 429 solution) be attributed to nutrients enrichment, the presence of toxic compounds and 430 unhealthy elements in treated wastewater notably reduced the plants vegetative growth 431 (length and width of leaves). M oreover, residual hydrocarbons in treated wastewater limited 432 plants access to essential nutrients that support their growth (Adam and Duncan, 2002). This 433 scientific conclusion was drawn following the observed differences in phenological 434 characteristics (leaf length and width) (significant at $5 \%$ level of confidence) between plants 435 irrigated with TWW and TPW $(3.9$ and $1.8 \mathrm{~cm} ; 6.1$ and $2.1 \mathrm{~cm}$ as length and width of TPW 436 lettuce and beets respectively). However, nutrients deficiency and imbalance played a critical 437 role in the poor leaf production and overall vegetative growth registered in plants with TWW 438 and TPW irrigation solutions in comparison to TPW +NUS. The impact of complex organics and 439 hydrocarbons were very apparent in mixed wastewater irrigated crops as suppressed leaf 440 growths were observed in lettuce and beets, with $50 \%$ of the beets completely inhibited after 441 germination.

\section{$442 \quad 3.4$. Chlorophyll concentration}

443 The impact of irrigation water solutions on green pigments in lettuce and beets plants are 444 presented in Figure 5. The results indicate the means and standard errors measured from 445 four (4) replicates of each treatment solution for both plant species. The green pigments 
446 including chlorophyll $a$ and $b$ were consistently maximum in plants with nutrients 447 supplemented solution. Analysis of variance conducted on the pigments produced by the 448 various treatment solutions showed a significant difference at $5 \%$ confidence level. Further 449 data analysis ( $P=0.05)$ confirmed that chl. $a$ and chl. b contents in plants with TPW and TPW 450 + NUS were unequal, and a significant difference also existed between TPW and TWW. The 451 chlorophyll contents in MWW irrigated leaves were the lowest and significantly different $(P=$ 452 0.05) from the TWW. These results highlight the significance of balanced nutrients and minerals in TPW + NUS treatment solution.

However, the higher chlorophyll contents in leaves with tap water treatment over the treated wastewater is an indication of possible inhibitory effect of residual toxic compounds and hydrocarbons in the latter on synthesis of chlorophyll molecules in the plants, and which may be responsible for the yellowing observed in some of the leaves mainly two of the beets' leaves. The finding supports previous investigation that metals (Rehman et al., 2009) and textile wastewater (Khan et al., 2011) have adverse impact on photosynthetic elements which are responsible for green pigments in vegetable plants. M oreover, as was reported in similar study (Urbano et al., 2017), nutrient deficiencies in the treated wastewater may have contributed to the yellow colouration mainly in beets as some of the tap water treated leaves possessed similar yellow colouration. However, following the previous report (Oyama et al., 2005) that iron and/or nitrate deficiency in reuse water could result to chlorosis in leaves, it can be inferred that lack of iron in the treated wastewater may have contributed to leaves chlorosis as nitrate was not a limiting factor. In contrast to the level of green pigments in MWW irrigated leaves, SGBP treated wastewater can serve as a potential source of irrigation stream requiring little polish treatment to improve effluent quality for agricultural reuse.

\subsection{Vegetative yield and plant length}

470 The fresh and dry weights of lettuce and beets plants irrigated with the various treatment 471 solutions are presented in Table 4, while shoot length and roots elongation are reported in 472 Figure $5 c \& d$. The results showed a significant (at $P=0.05$ ) difference in shoot fresh and dry 473 weights in all treatment solutions, and a huge difference between the TPW + NUS and other 474 irrigation solutions. This is very apparent in Figures 6 and 7 which show the above and below 475 ground of harvested crops treated with the various irrigation solutions. The poor vegetative 
yield in lettuce $(0.20 \mathrm{~g}$ average per plant) irrigated with the TWW is in agreement with the results found in similar study (Jesse et al., 2019) in which low yield (below $10 \mathrm{~g}$ fresh weight per plant) was reported for lettuce irrigated with diluted post-hydrothermal liquefaction wastewater (PHW) treated by sand and carbon filtration. The poor vegetative yield was majorly attributed to residual complex organic compounds and toxic elements which exerted inhibitory effects on plant development and growth (Jesse et al., 2019). For the beets, obtained results - $0.53 \mathrm{~g}$ (average of one beet crop irrigated with TWW) varied from that reported by (Oyama, 2008) who achieved on average nearly $41 \mathrm{~g}$ from silver beet plant irrigated with secondary treated domestic effluent. The wide variation in both studies is a function of factors such as wastewater source and characteristics, plant species and growth period. The influence of these parameters especially plant species and growth period could be seen in the yields reported for beets grown in nutrients medium with $13.6 \mathrm{~g}$ in this study and $168 \mathrm{~g}$ in previous work (Oyama, 2008).

The highest vegetative yield in plants with nutrients solution is a function of nutrients enrichment and minerals adequacy in the treatment stream. As was reported in earlier investigations relating to wastewater impact on lettuce grown in hydroponic system (Carvalho et al., 2018) and greenhouse (Urbano et al., 2017), nutrients deficiency in the present study contributed to the low yield recorded under TWW irrigation regime. This finding is in disagreement with the results reported previously (Pinto et al., 2010) which indicated that untreated domestic wastewater (greywater) had little or no significant impact on silverbeet biomass. The variation in results could be attributed mainly to wastewater characteristics and partly to the growth medium employed in the two studies as the buffering potential of the growing medium (soil) used in previous study may have played a key role in the high vegetative production in greywater irrigated silverbeet.

Similarly, there is significant difference $(P=0.05)$ in plant height and root lengths produced in the various treatment solutions. While there is a significant difference between the MWW and TWW treated plants, the stunted growth in TWW irrigated plants was because of early inhibitory effect of toxic compounds on the plants roots thus limiting nutrients accessibility in 504 irrigation solution. Hence, for improved effluent quality, partial or complete breakdown of 505 recalcitrant and complex organic compounds is crucial, and AOPs might be promising for this 
application. Among the AOPs, ozonation $\left(\mathrm{O}_{3}\right)$ is known as a simple, efficient and economical treatment for degradation of complex organics and hydrocarbons in wastewater (Jiménez et al., 2019; Rosal et al., 2010).

\section{Conclusion}

510 The suspended growth bioreactor (SGBR) has shown potential for biodegradation of mixture

511 of complex organic compounds in the mixed industrial and domestic wastewater to residual 512 carbon level of $209 \mathrm{mg} \mathrm{COD} / \mathrm{L}$. However, the phenological characteristics of the crops 513 irrigated with treated wastewater suggest the presence of compounds at concentrations that 514 have great tendency to inhibit plant roots development at the early stage and consequently 515 hindered plants access to available nutrients in reuse water for good vegetative development 516 and growth. Although the growth and yield outcomes in both crops under treated wastewater 517 irrigation were considerably low, there is significant difference in germination responses and 518 growth rates between the studied crops (lettuce and beets). While germination was rapid and uniform in lettuce, the response in beets was slow and non-uniform. Similarly, the rate of leaf emergence was greater in lettuce crop over the beets. However, leaf area and root elongation were higher in beet crop. The observed variations could be aligned to crop type and plant species, plant toxicity threshold, sensitivity to environmental and climatic conditions, and plant ability to strive in nutrients deficit environment. While, nutrients deficiency and imbalance contributed to the poor growth and productivity registered in both crops grown under treated wastewater irrigation regime, residual inhibitory compounds in reuse water played a dominant role in the overall poor performance and low yield outcomes. Although, the yield was relatively low in comparison to the nutrients solution, there is a positive indication for the reuse of mixed wastewater in agriculture.

Therefore, further studies are required to explore the benefits and limitations of reusing such treated wastewater in crop irrigation. Specifically, studies to ascertain the toxicity of residual substances in the treated wastewater on plant growth as well as understand the synergistic impact of nutrients balanced treated mixed wastewater on overall plant development are vital. Also, there is need for further research to explore the potential of suspended growth

534 biological process bioreactor at varying operational conditions for mixed wastewater 535 treatment. Another possible direction of further research could be to study post-treatment 
536 methods such as advanced oxidation processes to further improve the quality of treated

537 mixed wastewater. Any further treatment options need to be assessed for their implication

538 on crop yield as well as cost.

539 Acknowledgement

540 The first author sincerely thanks Petroleum Technology Development Fund (PTDF), Nigeria

541 for providing full financial sponsorship for PhD research at the University of Surrey, Surrey,

542 United Kingdom. Sincere thanks equally go to Caryn Jones, Tina Steinbrecher, Achame Shana,

543 Gregory Obiechefu and Anthony Amori whose valuable supports paved way to successful

544 completion of this work.

545 Funding

546 This work was fully supported by Petroleum Technology Development Fund (PTDF), Abuja,

547 Nigeria, under the PTDF Overseas Scholarship Schemes (OSS) for Human Capital Development

548 [grant number PTDF/ED/OSS/PHD/ POF/1109/17]. Other supports came from InRoot and

549 Water-Food scoping projects at University of Surrey as part of STFC Food Security Network

550 led by the University of Manchester [Grant number ST/P003079/1].

551 Conflict of interest

552 No potential conflict of interest was reported by the authors.

553 Ethical approval

554 This article does not contain any studies with human participants or animals performed by any

555 of the authors.

556

557 References

558 Abubakar, I.R., 2017. Access to sanitation facilities among nigerian households:

559 Determinants and sustainability implications. Sustain. 9, 1-17.

$560 \quad$ https://doi.org/10.3390/su9040547

561 Adam, G., Duncan, H., 2002. Influence of diesel fuel on seed germination. Environ. Pollut. $562 \quad 120,363-370$. 
Allen, R.G., Pereira, L.S., Raes, D., Smith, M ., 1998. Crop Evapotranspiration - guidelines for computing crop water requirements. FAO Irrigation and drainage paper 56. Food and Agriculture Organization, Rome, Italy. http://www.fao.org/docrep/x0490e/x0490e00.htm.

Amin, M .A.R.M.M., Kutty, S.R.M., Gasim, H.A., Isa, M.H., 2012. Impact of Petroleum Refinery Wastewater on Activated Sludge, in: 5th WSEAS International Conference on Environmental and Geological Science (EG). Vienna, Austria, pp. 110-115.

APHA, 1998. Standard M ethods for the Examination of Water and Wastewater., 20th ed. American Public Health Association, Washington, DC. https://books.google.co.uk/books/about/Standard_Methods_for_the_Examination_of. html?id=2BcoYAAACAAJ\&redir_esc $=y$.

Banik, S., M ukherjee, R., Ghosh, P., Karmakar, S., Chatterjee, S., 2018. Estimation of plant pigments concentration from tulsi (Ocimum sanctum Linn.): a six months study Understanding of the chaperone function of a-crystallin View project Plant Pigments Research View project. J. Pharmaccognosy Phytochem. 7, 2681-2684.

Brechner, M ., Both, A.J., 2013. Controlled Environment Agriculture - Hydroponic Lettuce Handbook [WWW Document]. URL http://cea.cals.cornell.edu/attachments/Cornell CEA Lettuce Handbook .pdf (accessed 12.3.19).

Cadoret, A., Conrad, A., Block, J.C., 2002. Availability of low and high molecular weight substrates to extracellular enzymes in whole and dispersed activated sludges. Enzyme M icrob. Technol. 31, 179-186. https://doi.org/10.1016/S0141-0229(02)00097-2

Carvalho, R. da S.C., Bastos, R.G., Souza, C.F., 2018. Influence of the use of wastewater on nutrient absorption and production of lettuce grown in a hydroponic system. Agric. Water M anag. 203, 311-321. https://doi.org/10.1016/j.agwat.2018.03.028

Chaudhry, G.R., Chapalamadugu, S., 1991. Biodegradation of halogenated organic compounds. Microbiol. Rev. 55, 59-79.

Chaves, I. de S., Silva, N.C.Q., Ribeiro, D.M., 2017. Effect of the seed coat on dormancy and germination in Stylosanthes humilis H. B. K. seeds. J. Seed Sci. 39, 114-122. 
Chow, K.K., Wang, J.Y., Tay, J.., 2001. Hydroponic cultivation of leafy vegetables in primary and secondary municipal wastewater. Acta Hortic 554, 139-146. https:// doi.org/10.17660/ActaHortic.2001.554.14

595

596

597

598

599

600

601

602

603

604

605

606

607

608

609

610

611

612

613

614

615

616

617 618

Chung, N.J., Cho, A.J.Y., Park, A.S.W., Park, A.B.J., Hwang, A.S.A., Park, A.T.I., 2008. Polycyclic Aromatic Hydrocarbons in Soils and Crops After Irrigation of Wastewater Discharged from Domestic Sewage Treatment Plants. Bull. Environ. Contam. Toxicol. 81, 124-127. https:// doi.org/10.1007/s00128-008-9398-5

Cirelli, G.L., Consoli, S., Licciardello, F., Aiello, R., Giuffrida, F., Leonardi, C., 2012. Treated municipal wastewater reuse in vegetable production. Agric. Water Manag. 104, 163170.

Deng, Y., Yuan, F., Feng, Z., Ding, T., Song, J., Wang, B., 2014. Comparative study on seed germination characteristics of two species of Australia saltbush under salt stress. Acta Ecol. Sin. 34, 337-341.

du Plessis, A., 2017. Global Water Availability, Distribution and Use, in: Freshwater Challenges of South Africa and Its Upper Vaal River. Springer Water. Springer, Cham, pp. 3-11. https://doi.org/https://doi.org/10.1007/978-3-319-49502-6_1

Dvorak, L., Svojitka, J., Wanner, J., Wintgens, T., 2013. Nitrification performance in a membrane bioreactor treating industrial wastewater. Water Res. 47, 4412-4421.

Egbuikwem, P.N., Naz, I., Saroj, D.P., 2019. Appraisal of suspended growth process for treatment of mixture of simulated petroleum, textile, domestic, agriculture and pharmaceutical wastewater. Environ. Technol. 1-17. https:// doi.org/https:// doi.org/10.1080/09593330.2019.1609097

El-Naas, M.H., Surkatti, R., Al-Zuhair, S., 2016. Petroleum refinery wastewater treatment: A pilot scale study. J. Water Process Eng. 14, 71-76. https://doi.org/10.1016/j.jwpe.2016.10.005

Elfanssi, S., Ouazzani, N., M andi, L. , 2018. Soil properties and agro-physiological responses of alfalfa (Medicago sativa L.) irrigated by treated domestic wastewater. Agric. Water 
FAO, 2017. Water for Sustainable Food and Agriculture: A report produced for the $G 20$

621

622

623

624

625

626

627

628

629

630

631

632

633

634

635

636

637

638

639

640

641

642

643

644

645

646

Presidency of Germany [WWW Document]. Food Agric. Organ. URL http://www.fao.org/3/a-i7959e.pdf (accessed 8.7.18).

Gandy, M., 2006. Water, Sanitation and the Modern City: Colonial and Post-colonial Experiences in Lagos and M umbai [WWW Document]. Hum. Dev. Occas. Pap. (19922007), HDOCPA-2006-06, Hum. Dev. Rep. Off. (HDRO), United Niations Dev. Program. URL https://ideas.repec.org/s/hdr/hdocpa.html (accessed 9.4.19).

Gray, D., 1975. Effects of Temperature on the Germination and Emergence of Lettuce (Lactuca Sativa, L.) Varieties. J. Hortic. Sci. 50, 349-361. https://doi.org/10.1080/00221589.1975.11514644

Hey, G., 2013. Application of chemical oxidation processes for the removal of pharmaceuticals in biologically treated wastewater. PhD Thesis. Lund University, Sweden.

IKEA, 2019. Indoor growing cultivators [WWW Document]. Inter IKEA Syst. B. V. URL http://www.ikea.com/gb/en/products/indoor-gardening/ (accessed 10.8.19).

Jesse, S.D., Zhang, Y., M argenot, A.J ., Davidson, P.C., 2019. Hydroponic Lettuce Production Using Treated Post-Hydrothermal Liquefaction Wastewater ( PHW ). Sustainability 11, 1-16. https:// doi.org/https:// doi.org/10.3390/su11133605

Jiménez, S., Andreozzi, M., M icó, M .M., Álvarez, M.G., Contreras, S., 2019. Produced water treatment by advanced oxidation processes. Sci. Total Environ. 666, 12-21. https://doi.org/10.1016/j.scitotenv.2019.02.128

Kanu, I., Achi, O.K., 2011. Industrial Effluents and Their Impact on Water Quality of Receiving Rivers in Nigeria. J. Appl. Technol. Environ. Sanit. 1, 75- 86.

Khan, M.G., Daniel, G., M. Konjit, A.T., Eyasu, S.S., Awoke, G., 2011. Impact of Textile Waste Water on Seed Germination and Some Physiological Parameters in Pea (Pisum sativum L.), Lentil (Lens esculentum L.) and Gram (Cicer arietinum L.). Asian J. Plant Sci. 14, 269273. 
Khan, S., Aijun, L., Zhang, S., Hu, Q., Zhu, Y.-G., 2008. Accumulation of polycyclic aromatic hydrocarbons and heavy metals in lettuce grown in the soils contaminated with longterm wastewater irrigation. J. Hazard. M ater. 152, 506-515. https:// doi.org/10.1016/J.JHAZM AT.2007.07.014

Kummerová, M., Zezulka, Š., Váňová, L., Fišerová, H., 2012. Effect of organic pollutant treatment on the growth of pea and maize seedlings. Cent. Eur. J. Biol. 7, 159-166. https://doi.org/10.2478/s11535-011-0081-1

Libutti, A., Gatta, G., Gagliardi, A., Vergine, P., Pollice, A., Beneduce, L., Disciglio, G., Tarantino, E., 2018. Agro-industrial wastewater reuse for irrigation of a vegetable crop succession under M editerranean conditions. Agric. Water Manag. 196, 1-14. https://doi.org/10.1016/J.AGWAT.2017.10.015

Lu, J., M a, Y., Liu, Y., Li, M ., 2011. Treatment of hypersaline wastewater by a combined neutralization-precipitation with ABR-SBR technique. Desalination 277, 321-324. https://doi.org/10.1016/j.desal.2011.04.054

Méndez-Arriaga, F., Torres-Palma, R.A., Pétrier, C., Esplugas, S., Gimenez, J., Pulgarin, C., 2009. Mineralization enhancement of a recalcitrant pharmaceutical pollutant in water by advanced oxidation hybrid processes. Water Res. 43, 3984-3991. https://doi.org/10.1016/j.watres.2009.06.059

Noni-M orales, D., Barros, D., Castro, S.A., Ortiz, C., 2019. Germination and seedling growth of the Chilean native grass Polypogon australis in soil polluted with diesel oil. Int. J. Phytoremediation 21, 14-18. https://doi.org/10.1080/15226514.2018.1523868

Ogbo, E.M., 2009. Effects of diesel fuel contamination on seed germination of four crop plants - Arachis hypogaea, Vigna unguiculata, Sorghum bicolor and Zea mays. African J. Biotechnol. 8, 250-253. https://doi.org/10.5897/AJB2009.000-9044

Oyama, N., 2008. Hydroponics system for wastewater treatment and reuse in horticulture. PhD Thesis. Murdoch University, Western Australia, Australia.

Oyama, N., Nair, J., Ho, G.E., 2005. Recycling of treated domestic effluent from an on-site wastewater treatment system for hydroponics. Water Sci. Technol. 51, 211-219. 
Pinto, U., Maheshwari, B.L., Grewal, H.S., 2010. Effects of greywater irrigation on plant growth, water use and soil properties. "Resources, Conserv. Recycl. 54, 429-435. https:// doi.org/10.1016/j.resconrec.2009.09.007

Popa, C., Favier, L., Dinica, R., Semrany, S., Djelal, H., Amrane, A., Bahrim, G., 2014. Potential 680 of newly isolated wild Streptomyces strains as agents for the biodegradation of a recalcitrant pharmaceutical, carbamazepine. Environ. Technol. 35, 3082-3091. https:// doi.org/10.1080/09593330.2014.931468

Pothour, G., 2017. Soil Temperature Conditions for Vegetable Seed Germination, in: M cClure, J. (Ed.), Garden Notes. Regents of the University of Califonia, Division of Agricultural and Natural Resources, Califonia, p. 114.

Reddy, J., 2019. Growing Beetroot Hydroponically - A Full Guide | Gardening Tips [WWW 687 Document]. Gard. Tips. URL https://gardeningtips.in/growing-beetroot-hydroponicallya-full-guide\#. -targetText=Best germination occurs within 7, in the hydroponic system directly. (accessed 12.3.19).

Rehman, A., Bhatti, H.N., Athar, H.-R., 2009. Textile Effluents Affected Seed Germination and Early Growth of Some Winter Vegetable Crops: A Case Study. Water. Air. Soil Pollut.

Rosal, R., Rodríguez, A., Perdigón-M elón, J.A., Petre, A., García-Calvo, E., Gómez, M.J., Agüera, A., Fernández-Alba, A.R., 2010. Occurrence of emerging pollutants in urban wastewater and their removal through biological treatment followed by ozonation. Water Res. 44, 578-588. https://doi.org/10.1016/j.watres.2009.07.004

Ruma, M., Sheikh, A., 2010. Reuse of wastewater in urban farming and urban planning implications in Katsina metropolis, Nigeria. African J. Environ. Sci. Technol. 4, 28-33. https:// doi.org/10.5897/AJEST09.106

Saliba, R., Callieris, R., D’Agostino, D., Roma, R., Scardigno, A., 2018. Stakeholders' attitude towards the reuse of treated wastewater for irrigation in M editerranean agriculture. Agric. Water Manag. 204, 60-68. 
Stepnowski, P., Siedlecka, E.M ., Behrend, P., Jastorff, B., 2002. Enhanced photo-degradation of contaminants in petroleum refinery wastewater. Water Res. 36, 2167-2172. https:// doi.org/10.1016/S0043-1354(01)00450-X

The World Bank, 2017. Water Resources M anagement [WWW Document]. URL https://www.worldbank.org/en/topic/ waterresourcesmanagement (accessed 8.11.18).

United Nations, 2017. The Sustainable Development Goals Report 2017 [WWW Document]. URL https:// unstats.un.org/sdgs/report/2017/ (accessed 8.7.18).

Urbano, V.R., M endonca, T.G., Bastos, R.G., Souza, C.F., 2017. Effects of treated wastewater irrigation on soil properties and lettuce yield. Agric. Water Manag. 181, 108-115. https://doi.org/10.1016/j.agwat.2016.12.001

Varjani, S.J., 2017. M icrobial degradation of petroleum hydrocarbons. Bioresour. Technol. 223, 277-286. https://doi.org/10.1016/j.biortech.2016.10.037

WHO, 2006. WHO Guidelines for the Safe use of Wastewater, Excreta and Greywater. Vol. I: Policy and Regulatory Aspects, World Health Organization. Geneva. https://doi.org/10.1007/s13398-014-0173-7.2

World Bank, 2017. A Wake Up Call: Nigeria Water Supply, Sanitation, and Hygiene Poverty Diagnostic. WASH Poverty Diagnostic. [WWW Document]. URL https://programme.worldwaterweek.org/Content/ProposalResources/allfile/siwi_broc hure_1.pdf

\section{Legend for figures}

Figure 1. A schematic set-up of laboratory suspended growth biological process (SGBP) bioreactor and hydroponic unit

Figure 2. Steady-state performance of suspended growth biological process with respect to removal of (a) COD and BOD (b) $\mathrm{NH}_{4}-\mathrm{N}, \mathrm{NO}_{3}-\mathrm{N}$, and TN (c) $\mathrm{PO}_{4}-\mathrm{P}$ (d) pH variation

Figure 3. Daily environmental condition and seed germination records with respect to (a) Temperature (b) Relative humidity (RH) (c) Lettuce germination (d) Beets germination. TPW: Tap water; M WW: M ixed wastewater; TWW: Treated wastewater; TPW +NUS: Tap water with nutrients solution

Figure 4. Effect of irrigation solutions on plant physiological development (a) Lettuce leaf number (b) Beets leaf number (c) Lettuce leaf length and width (d) Beets leaf length and 
733 width. TPW: Tap water; MWW: M ixed wastewater; TWW: Treated wastewater; TPW +NUS:

734 Tap water with nutrients solution

735 Figure 5. Effect of irrigation solution on green pigmnets production and plant growth (a)

736 Lettuce chlorophyll contents (b) Beats chlorophyll contents (c) Lettuce shoot and root length

737 (d) Beets shoot and root length. TPW: Tap water; MWW: M ixed wastewater; TWW: Treated

738 wastewater; TPW +NUS: Tap water with nutrients solution; FL: Fresh leaf

739 Figure 6. Images of above and below ground of harvested (a) lettuce crop (b) beets crop,

740 irrigated with (i) TPW +NUS (ii) TPW (iii) TWW (iv) M WW. TPW: Tap water; MWW: M ixed

741 wastewater; TWW: Treated wastewater; TPW +NUS: Tap water with nutrients solution

742 Figure 7. Images of root density of harvested (I) lettuce crop (II) beets crop, irrigated with

743 row (a) TPW +NUS (b) TPW (c) TWW (d) MWW. TPW: Tap water; M WW: M ixed wastewater;

744 TWW: Treated wastewater; TPW +NUS: Tap water with nutrients solution

746 Legend for tables

747 Table 1. Characteristics of model mixed wastewater used in the present research

748 experiments

749 Table 2. Bioreactor operational start-up and conditions

750 Table 3. Physicochemical properties of the mixed and treated wastewaters and other

751 irrigation solutions, and irrigation water quality guidelines

752 Table 4. Effect of irrigation solutions on shoots and roots of lettuce and beets crops 